\title{
COLECIONAR PAÍSES E TERRITÓRIOS: UMA PROPOSTA DE CONTABILIZAÇÃO DE LUGARES VISITADOS
}

\author{
João Sarmento \& Patrícia Lopes
}

\begin{abstract}
RESUMo
Colecionar é uma curiosa atividade humana, que consiste na reunião e guarda de objetos selecionados. Tem inúmeros formatos e caraterísticas. A coleção de lugares, isto é, a coleção da visita a esses mesmos lugares não é uma prática recente, mas no contexto da mobilidade das sociedades contemporâneas e da sociedade em rede e de consumo, tem adquirido uma importância grande. Ainda que possa não ser a principal motivação da viagem, e que possa ser mais ou menos inconsciente, a coleção de lugares e em consequência, a contabilização das viagens, é um ato social, que à semelhança de outras coleções existe para ser partilhada, comparada e mostrada. Este artigo debruça-se sobre esta prática, que está intimamente ligada às viagens e ao turismo. Por um lado, analisa uma questão central da coleção de lugares e territórios, que é a definição da coleção, isto é, quais os seus limites, e quais os seus "objetos". Esta discussão permite refletir sobre a forma como dividimos o mundo, nomeadamente no contexto da contabilização de viagens. Por outro lado, propõe-se aqui uma forma de contabilizar lugares ou territórios visitados que não atende unicamente ao facto de se ter estado num determinado lugar ou território, mas que inclui também outras variáveis como o tempo de permanência, as distâncias-tempo dos destinos, a perigosidade dos mesmos e a maior ou menor facilidade em entrar nesses territórios. Entrevistas a oito viajantes com grande experiência permitiram discutir e ajustar as ponderações destas mesmas variáveis, por forma a construir um índice compósito.
\end{abstract}

PALAVRAS-Chave

Coleções; contabilizar; índice de viajantes; viagens

\section{COLLECTING COUNTRIES AND TERRITORIES: A PROPOSAL FOR COUNTING VISITED PLACES}

\begin{abstract}
Collecting is a curious human activity, which consists of meeting and guarding selected objects. It has numerous formats and features. The collection of places, that is to say, the collection of the visit to places, is not a recent practice, but in the context of contemporary, mobile, networked and consumption societies, it has acquired great importance. Although it may not be the main motivation for a trip, and may be more or less unconscious, the collection of places and, consequently, place counting, is a social act. Like other collections it exists to be shared, compared and shown. This article examines this practice, which is closely linked to travel and tourism. On the one hand it analyses a central question of the collection of places and territories, which is the definition of the collection itself, that is, its limits, and its "objects". This discussion allows us to examine how we divide the world, namely in the context of counting visited places. On the other hand, this paper makes a proposal on how to count visited places, which not only accounts for the fact that someone was in a particular place or territory, but it also includes other variables such as the length of stay, time distance to destinations, the degree of dangerousness of the destination, and the easiness of entering these places or territories. Interviews with eight experienced travellers allowed for a discussion and weight adjustment of these same variables, in order to construct a composite index.
\end{abstract}


É um viajante a sério? Onde já esteve? Em que posição está? Em que posição esteve? Onde está agora? (...) Partilhe com os amigos. Vamos! Junte-se a nós na estrada para todo o lado (MTP 2015)

\section{INTRODUÇÃO}

Colecionar é um processo ativo voluntário, seletivo e emocional de juntar e possuir objetos ou experiências, arredando-os da sua vida de uso comum (Pearce, 1992). Implica uma certa paixão, muitas vezes um conhecimento detalhado das coleções em causa, e um entendimento de processos de catalogação e arquivo. Belk (2006) defende que colecionar é uma atividade essencialmente anti-materialista, pois quando um objeto entra numa coleção deixa de ser uma mercadoria fungível, isto é, passa a ser um objeto singular que não mais está disponível para ser trocado por um outro de valor semelhante. Acrescenta Belk (2006) que o seu valor reside precisamente na contribuição que dá à coleção como um todo.

Uma substancial parte das coleções de objetos não implica grande mobilidade por parte do colecionador, podendo haver, no entanto, mobilidade dos objetos colecionados. Frequentemente são coleções construídas de forma regular, podendo implicar, dependendo do grau de envolvimento do colecionador, encontros nacionais ou internacionais, para mostras, trocas, compras e vendas. As coleções de moedas e selos em particular, apesar de serem objetos com proveniências diversas, geralmente não pressupõem viagens aos locais de origem. Há no entanto coleções de objetos (ou colecionadores de certos objetos), que frequentemente se constroem através de viagens, como por exemplo a coleção de areia de praias diferentes, ou de objetos que se recolhem durante as viagens como ímanes para frigoríficos ou máscaras, e que de algum modo adquirem, juntamente com os lugares e contextos em que são adquiridos, um significado particular para quem os coleciona e que fazem parte de narrativas de viagem.

Este artigo debruça-se sobre as coleções que são feitas com os lugares, países ou territórios que se visitam, ou seja, a coleção é a presença física do colecionador nesses mesmos lugares. Tal como refere Timothy (1998, p. 126), colecionar lugares refere-se a "um processo onde localizações visitadas são enumeradas, existindo um desejo de visitar mais lugares por razões de competição". Os lugares podem ser países, mas podem ser mais específicos, como diversas linhas geodésicas (Timothy, 1998), lugares património da humanidade (King \& Prideaux, 2010) ou marcos de fronteira. Podem também ser experiências, como festivais e concertos, campeonatos de futebol, prémios de fórmula 1, etc. Em certo sentido são coleções imateriais, que não implicam trazer os lugares para casa, nem colecionar objetos. Podem pressupor a certificação de ter estado lá, através de carimbos de passaporte, fotografias, ou mesmo a coleção de objetos. Um dos antecedentes desta prova, caída em desuso, é sem dúvida o postal ilustrado, que 
tinha a função, entre outras, de transmitir a alguém a ideia de "eu estive aqui" (Urry \& Crashaw, 2002). Ao longo deste artigo optou-se por usar os termos lugar e território. Mesmo correndo o risco de alguma simplificação, o primeiro remete para uma relação de alguma subjetividade entre o viajante e o espaço, e pode adquirir escalas muito variáveis, desde uma praia ou um café até um país. O segundo articula-se em grande medida com a delimitação e identificação política de espaços, como seja o caso da definição de Estados e do seu reconhecimento pelas Nações Unidas'. Localização é um termo preterido aqui, pois sinaliza de algum modo uma precisão, lembrando coordenadas geográficas, latitudes e longitudes, o que não se alinha com a discussão que aqui se faz.

Colecionar lugares é assim um tipo específico de coleção pois implica uma mobilidade do colecionador que não é comum a muitas outras coleções. Ao mesmo tempo, porque existe uma ideia, socialmente aceite, de que ter estado num lugar acrescenta conhecimento sobre o mundo (Timothy, 1998), a coleção de lugares oferece uma credibilidade e prestígio a quem os visita ${ }^{2}$. Frequentemente, ao colecionarem lugares, os colecionadores, que podem até certo ponto ser considerados viajantes, satisfazem necessidades de autoestima, e procuram a admiração e reconhecimento de vizinhos, amigos, familiares e os seus pares viajantes. Colecionar neste sentido, refere-se a pessoas para quem uma motivação de viagem é adicionar uma atividade, lugar ou destino particular a um portfolio. Estas pessoas colecionam aspetos de uma experiência turística, geralmente mais vasta. Este facto é bem reconhecido há muito por operadores turísticos e agências de viagem, que desenham itinerários que permitem colecionar determinados destinos e lugares (King \& Prideaux, 2010).

Como a maior parte das coleções, colecionar lugares implica a enumeração desses mesmos lugares, ou seja, saber quais os limites da coleção que se está a construir. Visitar o mundo todo, na verdadeira aceção do termo, implicaria ter estado corporeamente em todas as suas partes, o que é humanamente impossível. Deste modo, a partição do mundo em partes maiores do que aquela que o corpo humano pode ocupar - notavelmente a divisão à escala do Estado - permite ter uma ideia da coleção que estamos a falar. Apesar deste processo de elaboração desta partição ser complexo e consumidor de tempo, tem já uma longa história, e ao longo do tempo várias instituições e organismos têm tido um papel importante nos diversos tipos de acreditação que estas partições podem ter. Ao mesmo tempo, apesar de contar países ou territórios ser um assunto individual, é um processo que adquire significado quando partilhado com outras pessoas, especialmente com outras pessoas que estão implicadas no mesmo tipo de coleção (Pearce, 1992). Isto é naturalmente amplificado hoje em dia pelas possibilidades que os social media abrem. Deste modo, a criação de clubes reservados cujos membros discutiam, apresentavam e partilhavam as suas experiências de viagem é um passatempo

\footnotetext{
'Para uma discussão mais detalhada da genealogia dos conceitos de lugar e território ver Cresswell (2014) e Elden (2010).

${ }^{2}$ Esta ideia não é no entanto consensual, e há vários escritores e pensadores que escreveram notavelmente sobre lugares distantes, sem saírem das suas secretárias ou das suas cidades: Henry Thoreau, que nunca saiu dos Estados Unidos, fez disso mesmo uma virtude; a poetisa Emily Dickinson, considerava que "fechar os olhos é viajar"; Xavier de Maistre, escritor francês do século XIX tem como principais obras Viagem ao redor do meu quarto, e Expedição noturna ao redor do meu quarto (Theroux, 2012).
} 
antigo, geralmente das elites urbanas dos países mais desenvolvidos. Mais ainda, colecionar, seja o que for, era, nas sociedades pré-consumo, uma atividade da "alta cultura".

Nos dias de hoje, em que viajar se tornou muito fácil para uma parte significativa da população, e em que vivemos numa era de mobilidade (Sheller \& Urry, 2006), definir o que é um viajante experiente é um exercício complexo3. Há assim muitas perspetivas sobre como abordar esta questão: países visitados, carimbos no passaporte, tempo necessário para fazer a mala, objetos que se levam numa viagem, problemas durante a viagem, tempo despendido em cada destino, visita a destinos perigosos, etc. Jorge Sánchez, um grande viajante contemporâneo, faz uma análise interessante no seu site, e inclui o tempo líquido em viagem como fator fundamental: de zero a 10 anos, turista; de 10 a 20 anos, viajante; mais de 20 anos, connoisseur (Sánchez, 2018).

Este artigo pretende analisar o processo de contagem enquanto contabilização das viagens, como parte de um processo de coleção. Após fazer uma revisão da importância dos clubes de viagem que foram criados sobretudo a partir do século XIX, lugares onde as elites apresentavam e discutiam explorações e lugares exóticos e longínquos, analisam-se as dinâmicas e metodologias da contabilidade de territórios feitas por diversos organismos. Seguidamente apresenta-se uma proposta para uma partição de territórios à escala global, e propõe-se uma forma de contabilização que tem em consideração o número de territórios visitados, a duração de tempo aí despendido, as distâncias percorridas, a perigosidade dos destinos, bem como o grau de dificuldade em aceder a esses mesmo territórios. Mais do que obter uma fórmula quase mágica, pretende-se promover a discussão em torno das viagens enquanto coleção e examinar algumas contradições e complexidades inerentes a este processo. Esta discussão faz-se com a colaboração de um conjunto de oito viajantes experientes, mas muito distintos entre si, que foram selecionados por conveniência. Todos foram entrevistados acerca da maior ou menor importância dos critérios adotados.

\section{Clubes e Sociedades: NARRAR E CONTAR Viagens}

Desde sempre que as pessoas narraram de alguma forma as viagens que empreenderam. Registos antigos de viajantes extraordinários incluem as viagens de Heródoto, de São Paulo, de Xuanzang, de Ibn Battuta ou Marco Polo (Gosh \& Stearns, 2008). A partir do século XVI, as inovações na construção e tecnologia naval contribuíram profundamente para a explosão das viagens e comércio marítimo entre a Europa e o resto do mundo, e com estas assistiu-se a uma transformação das perceções do mundo (Livingstone, 1992). A ciência moderna, o iluminismo, o interesse pelas viagens, pela exploração do mundo (Heffernan, 2003), trouxeram inúmeros factos, descobertas e narrativas sobre lugares distantes, que fascinavam grandes audiências, sobretudo urbanas. A receção efusiva de Alexander von Humboldt em Berlim, Paris ou Londres, no regresso das suas viagens, revela bem o interesse do público por estas narrativas (Wulf, 2016).

${ }^{3}$ Note-se no entanto que uma boa parte da população mundial nunca viajou. Apenas um em cada dez Chineses (população de 1,4 mil milhões) tem passaporte, sendo que esta percentagem é de $56 \%$ em relação aos Americanos. 
No final do século XVIII o entusiasmo exploratório deixou de ser apenas um empreendimento dependente de recursos individuais, mas passou sobretudo a ter um enquadramento de novas estruturas institucionais, estatais ou não, que se dedicavam a financiar a exploração e a descoberta geográfica (Heffernan, 2003). O novo ímpeto que a Revolução Francesa e as guerras napoleónicas trouxeram às Ciências da Cartografia e Topografia, estiveram na origem da formação de diversas sociedades de Geografia nas principais cidades europeias (Paris, 1821; Berlim, 1828; Londres, 1830) e mundiais (México, 1833; Brasil, 1838), que se vieram juntar a outras sociedades científicas já existentes, nas áreas da História Natural e Botânica, por exemplo. Todas elas promoviam a exploração e as viagens, dispondo de recursos financeiros e materiais, e publicando e divulgando descobertas e narrativas de lugares distantes, e estavam profundamente implicadas de diversas formas em projetos imperiais.

Tal como refere Livingstone (1991), a Royal Geographical Society resultou do crescimento da Associação Africana e do Raleigh Club, este último um dining club de viajantes, fundado em 1827, e que era já fruto de um outro clube apropriadamente chamado The Travellers Club, formado em 1819. O The Travellers Club era direcionado para "senhores que tinham viajado para fora das Ilhas Britânicas a uma distância de pelo menos 800 milhas de Londres em uma linha direta"4. Este tipo de clubes, quase exclusivamente masculino, tinha uma função social específica, estabelecendo uma articulação com avanços científicos, servindo para a discussão entre as elites de viagens e lugares exóticos, e alimentando a imaginação de um público ávido de imagens, mitos e aventuras. Para os seus membros, o clube tinha estabelecido "a tradição de jantar com especialidades de qualquer parte do mundo em que o anfitrião estivesse viajando: os clientes em ocasiões determinadas consumiam renas de Spitzbergen, bolo de centeio de North Cape, bagas cristalizadas da Lapônia - tudo regado a jarros de conhaque sueco" (Livingstone, 1991, p. 166). O coração de África, o Árctico, o Outback Australiano, o Everest e a Antártida, entre outros, ocuparam as sociedades e clubes até ao século XX.

Tudo naturalmente se transformou, quer com o desenvolvimento do turismo em si, e do turismo de massas em particular, que passou a levar milhões de pessoas a viajar por lugares que eram muito remotos nos finais do século XIX e durante mesmo boa parte do século XX, quer com as diferentes formas de difusão de imagens e de conhecimento do mundo, particularmente com a fotografia no final do século XIX, o cinema a partir do início do século XX, a televisão no pós segunda grande guerra (Beeton, 2005) e muito mais recentemente com a Internet e as redes sociais (Jansson, 2017).

Hoje em dia há diversas organizações que dividem o mundo em partes (países e territórios) para diversos fins. Alguns dos mais antigos clubes ainda existem, como o The Travellers Club (ver acima) ou o Travelers' Century Club (TCC), fundado em 1954, cujo requisito de entrada é ter-se visitado pelo menos cem países, ou hoje em dia territórios, dos quais reconhece 324. Num outro registo, mas servindo de base para muitas das divisões do mundo, estão as Nações Unidas, que reconhecem 193 Estados Membros, com igual representação na Assembleia das Nações Unidas. O Estado da Palestina e o Vaticano são Estados Observadores Permanentes não membros, sendo que Estados

Retirado de www.thetravellersclub.org.uk 
como a República da Abcásia, o Kosovo, a Ossétia do Sul ou a República Árabe Saariana Democrática, entre outros, apesar de reconhecidos por pelo menos um Estado Membro das Nações Unidas, não são reconhecidos por esta organização.

A vontade de viajar e de ser reconhecido como grande viajante está presente em alguns destes clubes e organizações e na construção de uma comunidade imaginada (Anderson, 2006). Os membros do TCC que tiverem viajado por todos os 324 territórios que o clube identifica, recebem um globo de cristal como reconhecimento dos seus feitos. Até hoje, 15 membros completaram esta coleção. O reconhecimento, prestígio ou mesmo fama é central no percurso de Charles Veley, um viajante americano. No ano de 2000, este dirigiu-se aos escritórios do Guinness World Records em Londres, com os seus passaportes, fotografias e outras provas de ter visitado diversos territórios, com o propósito de obter o título de "homem mais viajado do mundo". A reação do presidente do TCC foi de que seria impossível certificar as reivindicações de Veley, pois o clube opera num sistema de confiança, não havendo forma de confirmar a veracidade das suas alegações. Em resultado, o Guinness World Records decidiu deixar de atribuir o reconhecimento de pessoa mais viajada do mundo. Por seu lado, Veley criou em 2005 a plataforma Most Travelled People (MTP), que recorrendo à participação dos seus membros, que propõem e discutem partições, divide atualmente o globo em 874 partes (Julho de 2018). O MTP pretendeu "criar uma comunidade e standards para viajantes extremos". Apesar de ter deixado cair o reconhecimento da pessoa mais viajada do mundo, o Guinness World Records atribui diversos prémios de reconhecimento a viajantes, como seja o atribuído em 2017 à Americana Cassie de Pecol, por ter visitado 196 países em menos de dois anos, reduzindo assim em mais de um ano o tempo que o seu antecessor tinha necessitado. Algumas destas plataformas permitem contabilizar uma série de lugares específicos e não apenas os territórios que aqui discutimos. Estes vão desde cidades capitais, lugares classificados como património mundial pela Unesco, Restaurantes com estrelas Michelin, praias, fronteiras, etc.

\section{A DIVISÃo DO MUNDO E OS LIMITES DA COLEÇÃo}

Marca britânica lança Cork Globe, um globo de cortiça onde é possível marcar, com um pionés, os locais já percorridos. (Público, 3 de fevereiro de 2014)

É possível que o nível mais simples de hierarquizar a quantidade de viagens de uma pessoa se possa fazer através do número de países já visitados. Partindo dos 193 países reconhecidos pelas Nações Unidas, basta simplesmente indicar aqueles onde já se esteve. Mas uma tal contabilidade nada nos diz acerca dessas visitas, isto é, se foram muitas, por muito ou pouco tempo, e em que espaços dentro desses mesmos países se esteve. Mais ainda, não distingue entre uma visita a um país com mais de 17 milhões de quilómetros quadrados como a Rússia, de uma outra ao Liechtenstein, que tem uma área sensivelmente igual à do concelho de Guimarães (Portugal). Com esta metodologia cada país visitado "conta" o mesmo, e apenas uma vez. Deste modo, partindo destes mesmos 193 países, procurou-se criar divisões mais homogéneas, valorizando sempre a 
estadia em territórios político-administrativas diferentes. Em alguns casos, esta metodologia não diferiu muito da seguida por algumas plataformas já indicadas (ver Tabela 1). No entanto, optou-se por não fazer divisões em países com uma área já de si reduzida, como aquela feita pelo MTP (transformar os 26 cantões da Suíça em 26 territórios ou os 16 estados constituintes da Alemanha em 18 territórios) ou pelo The Best Travelled (TBT). A decisão passou por identificar a mediana da área dos 193 países (que se situa entre os 120.000 e $130.000 \mathrm{~km}^{2}$ ), e definir que não se dividiriam territórios com menos de $200.000 \mathrm{~km}^{2}$, por forma a não se obterem áreas menores do que esta mediana. Quando há uma divisão territorial/geográfica marcante (Portugal continental, Açores e Madeira por exemplo), adotam-se estas divisões. Quando a densidade populacional é muito baixa (inferior a 40 habitantes por $\mathrm{km}^{2}$ ), não se dividem territórios, mesmo que tenham uma área superior a $200.000 \mathrm{~km}^{2}$. Alguns casos são a Gronelândia, o Estado do Amazonas no Brasil, ou a Austrália. Reconheceram-se assim 838 territórios, que foram cartografados e integrados num Sistema de Informação Geográfica (Figura 1).

\begin{tabular}{|c|c|c|c|}
\hline ORGANIZAÇÃo & INÍCIO & Membros (JulHo 2018) & Países a Territórios \\
\hline Nações Unidas & 1945 & & $193(2018)$ \\
\hline Guinness World Records & 1954 & & $249(2003)$ \\
\hline Travelers' Century Club (TCC) & 1954 & +1400 & $324(2018)$ \\
\hline Most Traveled People (MTP) & 2005 & 18265 & $874(2018)$ \\
\hline The Best Travelled (TBT) & & 19891 & 1281 \\
\hline Greteast Globetrotters & 2011 & 477 & 1461 (pontos) \\
\hline Shea International Standards Organizations (SISO) ${ }^{5}$ & & & 3.978 \\
\hline Nossa proposta & & & 838 \\
\hline
\end{tabular}

Tabela 1: Seleção de organizações que dividem a terra em territórios

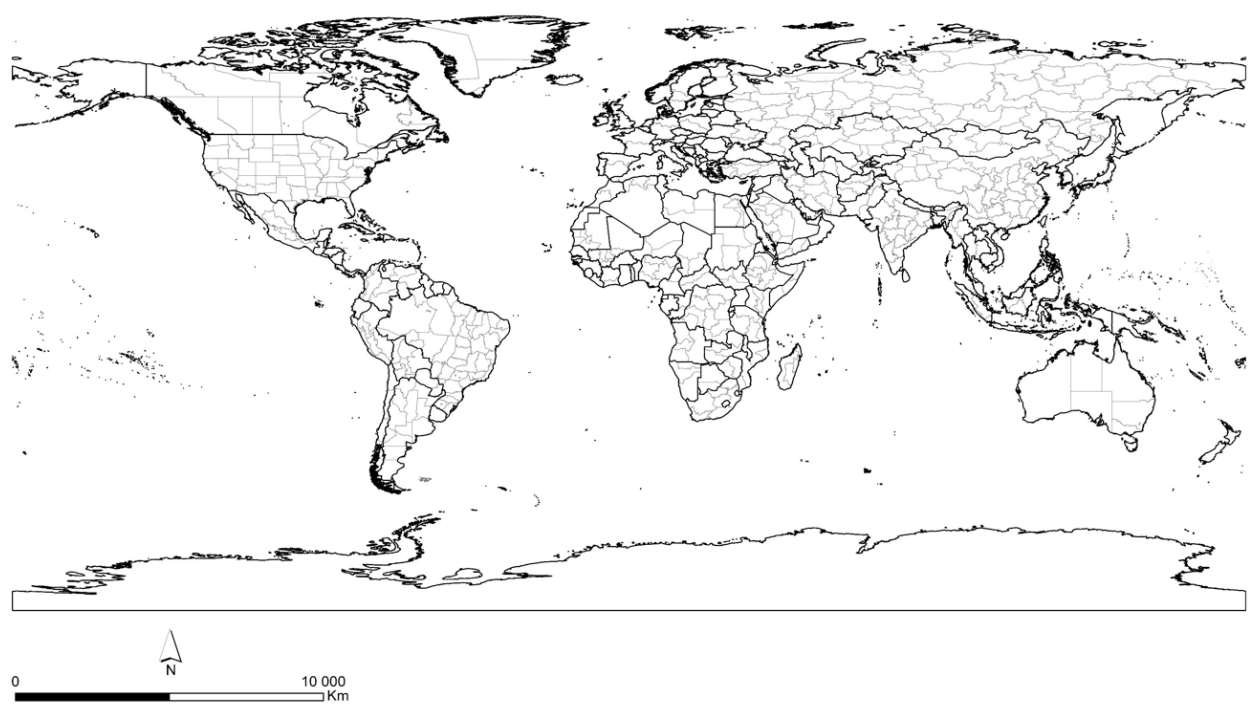

Figura 1: Divisão do mundo

${ }_{5}^{5}$ Parte da versão de 2003 dos "Códigos para a representação dos nomes dos países e das suas subdivisões - Parte 2: País subdivisão código" - ISSO 3166-2, que inclui 3.931 territórios. 


\section{CONTABILIZAR VIAGENS}

Ainda que a divisão territorial aqui proposta procure criar unidades territoriais um pouco mais homogéneas, isto dentro de um contexto de diversidade político-administrativa pré-existente, algumas divisões estão abertas a discussão e revisão. No entanto, como já referido, o ter visitado um território (1 para sim e o para não), nada nos diz sobre as caraterísticas das visitas em si, e neste sentido, decidiu-se introduzir algumas variáveis que não se encontram nas formas de contabilizar viagens que já existem (Figura 2). As primeiras três referem-se a uma quantificação de cada uma dessas visitas e as restantes três a uma qualificação desses destinos em relação a uma determinada origem:

$\mathrm{b}=\mathrm{O}$ número de vezes que se visitou cada um destes 838 territórios;

$x=O$ número total de noites em que se permaneceu em cada um dos territórios;

$y=O$ número de dias seguidos que se permaneceu nestes territórios;

$\mathrm{z}=\mathrm{A}$ distância em tempo da origem;

$\mathrm{W}=$ A perigosidade do destino;

$\mathrm{k}=$ Grau de dificuldade em ter autorização para entrar nesse território.

As três primeiras variáveis são indicadas pelos viajantes. As últimas três são calculadas previamente. $O$ índice que aqui propomos assume que visitar mais vezes um território pode trazer um acréscimo de conhecimento e de experiência de viagem que deve ser considerado (Figura 3). Em parte tenta valorizar os viajantes que repetem destinos, que retornam a um determinado território para verem lugares que não conhecem, e pretende contrariar a ideia de que o viajante experimentado é aquele que já foi a muitos países, mesmo que apenas uma só vez. Deste modo o número de visitas a um território é multiplicado por 10\%, que se soma à unidade que se obtém referente à visita desse mesmo território (visitar França sete vezes resulta num total de 1,7 ). Ao mesmo tempo valoriza-se o número total de noites em que se permanece num determinado território. Sem dúvida que não é o mesmo visitar a Bélgica três vezes, por períodos de dois dias, ou ter lá estado três vezes também, mas por períodos de um mês. Criaram-se cinco classes referentes ao número total de noites num determinado território, que resultam em bonificações. Os destinos onde se permanece menos de 30 dias não têm qualquer bonificação. Naturalmente que percebemos que o tempo de permanência num destino não é diretamente proporcional à interação e experiência que possam existir, pois há inúmeros contextos e variáveis que podem ter influência neste aspeto. Doris Lessing (1994, p. 138) explicou esta relação em Under my Skin, a sua autobiografia, escrevendo "pode-se viver durante meses num local, até anos, e ele não nos tocar, mas um fim de semana ou uma noite noutro, e sentimo-nos como se todo o nosso ser tivesse sido salpicado pelo equivalente a um vento cósmico". Ainda assim, tempos mais prolongados abrem oportunidades de interação com os lugares, e estes foram considerados como contributo para a experiência dos viajantes. Um viajante que permaneça num território durante três ou seis meses, terá que adaptar a sua permanência a um estilo de vida que se assemelhe menos a um turista, e terá oportunidades de interação distintas que são 
aqui valorizadas. Deste modo, foram criadas cinco classes para o total de dias consecutivos num território, que preveem bonificações.

Como já mencionado, três critérios foram calculados previamente e são independentes do perfil do viajante. Como limitações têm o facto da origem da viagem estar ancorada à cidade do Porto, Portugal, e o passaporte do viajante ser Português. Assim, a distância em tempo da origem ao destino foi calculada a partir do Porto para cada um dos 838 territórios $^{6}$, que permite fazer uma simulação do número de horas de viagem (Figura 2). Naturalmente que estamos a lidar com um sistema dinâmico e este tempo de viagem, sobretudo quando diz respeito a voos e ligações aéreas, refere-se a um momento particular no tempo, e pode variar significativamente com a época do ano, o dia da semana, e outras variáveis. Em todo o caso, assume-se que a fricção da distância tempo tem influência na dificuldade da viagem e por isso deve ser tida em conta, isto é, para um viajante residente em Portugal, não é o mesmo visitar uma parte da Espanha continental ou a Nova Zelândia, e não é o mesmo deslocar-se para um destino que está a 2.000 quilómetros na Alemanha, ou a uma distância absoluta semelhante em quilómetros, mas na Argélia. Criaram-se sete classes de tempo, a que correspondem diversas bonificações.

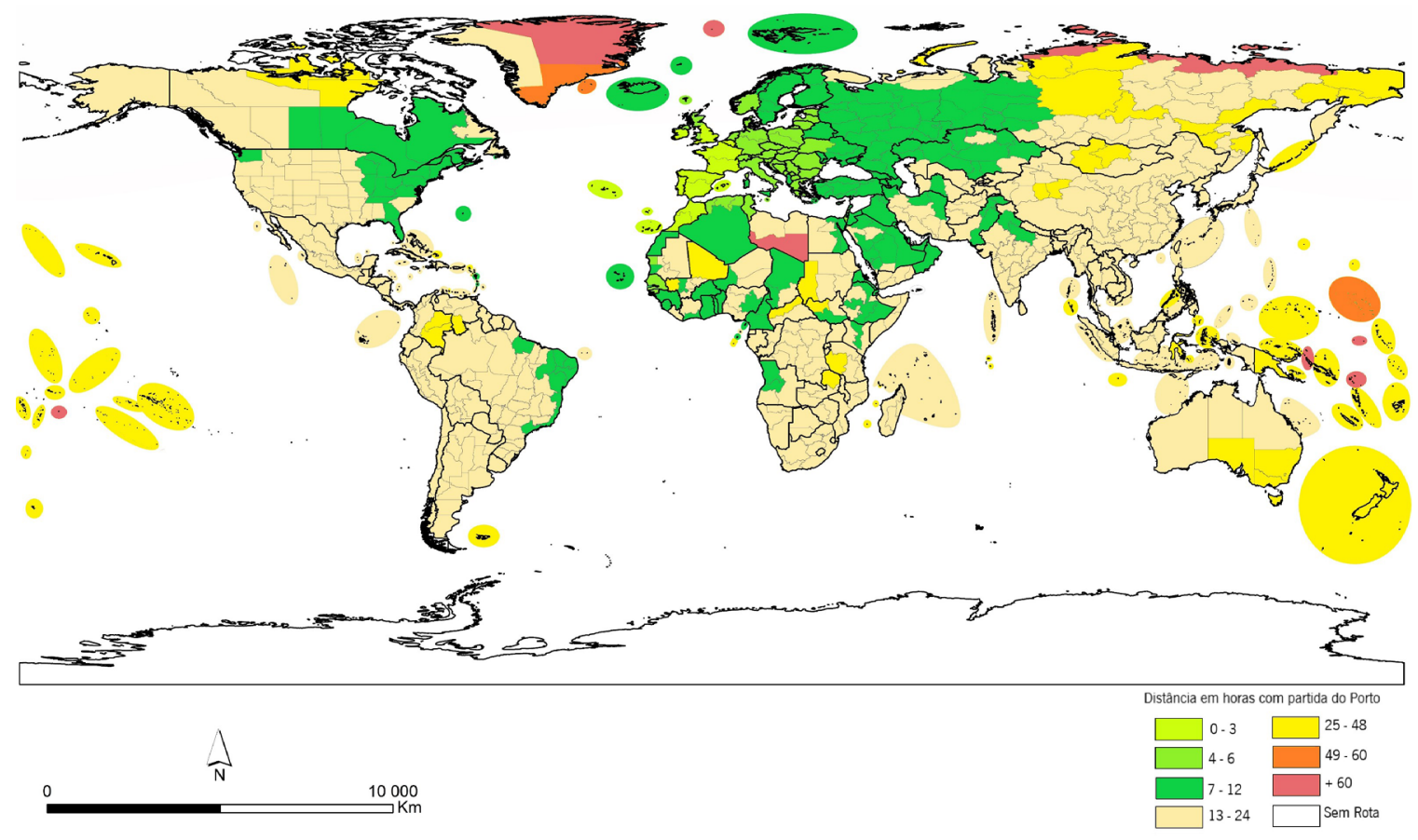

Figura 2: Simulação das distância-tempo com origem no aeroporto do Porto, Portugal

\footnotetext{
${ }^{6}$ Utilizando o site www.rometorio.com
} 


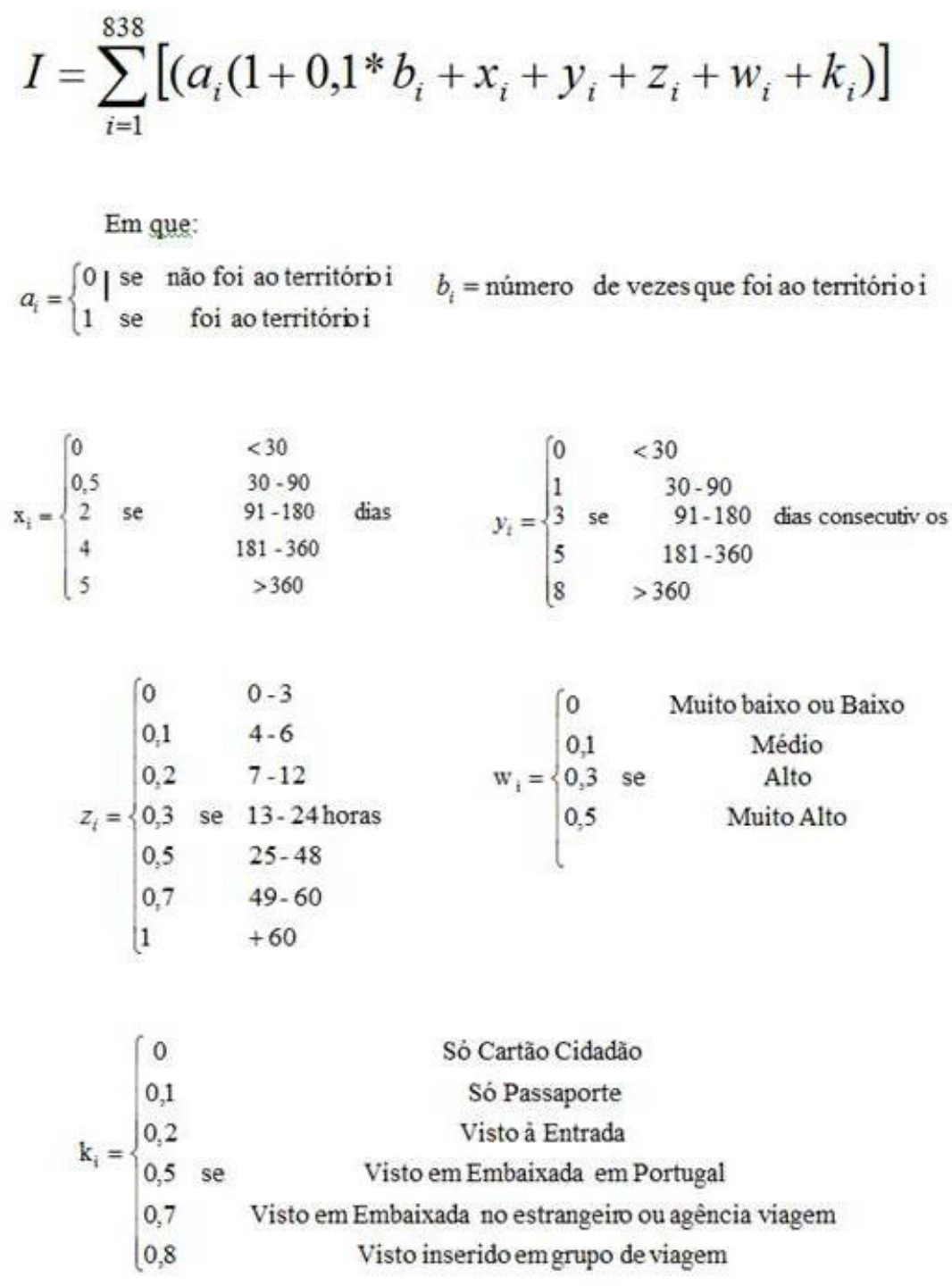

Figura 3: Índice de territórios visitados

Um outro aspeto que foi tido em conta prende-se com a perigosidade do destino, que permite bonificar as viagens para destinos indicados como mais inseguros e que por isso mesmo supostamente acarretam um maior grau de dificuldade na viagem. Para este efeito utilizou-se o Global Peace Index de 2017 do Instituto de Economia e Paz. Às cinco categorias existentes (de 1, mais pacífico, até 5, menos pacífico) atribuíram-se bonificações às três mais perigosas. Finalmente valorizou-se a dificuldade de obtenção de autorização para visitar estes territórios, partindo do pressuposto que o viajante tem um passaporte português. Assim, a) não recebem bonificação os destinos para onde não é necessário passaporte ou qualquer tipo de visto (todos da União Europeia por exemplo), e recebem bonificação crescente aqueles destinos para os quais b) só é necessário passaporte (Ucrânia ou Brasil, por exemplo); c) é necessário visto à chegada (Quénia ou Vietname, por exemplo); d) é necessário visto que se pode tratar em embaixada/consulado 
em Portugal (Rússia ou Índia, por exemplo); e) é necessário visto que se tem que tratar em embaixada/consulado no estrangeiro ou através de agência de viagem (Myanmar, por exemplo); f) é necessário visto que só pode ser tratado em viagem de grupo através de agência de viagem (Coreia do Norte e Butão). Esta informação foi recolhida no Portal das Comunidades Portuguesas, do Ministério dos Negócios Estrangeiros, em Março de 2018, e está sujeita a atualizações permanentes.

Construiu-se assim uma fórmula que permite valorizar estas variáveis, que foram calibradas sucessivamente para que o efeito que as valorizações provocam seja o mais ajustado possível. Para o efeito da calibração das bonificações já referidas, recorreu-se a um painel de oito pessoas com grande experiência de viagem e que realiza viagens de natureza muito diversa (Tabela 2). As entrevistas (presenciais, por telefone ou mensagens de email/Facebook) serviram para perceber e discutir de que forma estes viajantes contabilizam ou não as suas viagens, de que modo estas são uma forma de coleção, e que importância têm os critérios por nós definidos. Por ordem decrescente de importância no somatório cumulativo que cada viajante atribuiu aos seis critérios (de 1, mínimo, a 5, máximo), foram indicados o número de territórios visitados, o número de visitas a esses mesmos territórios, a duração total das visitas, a distância a que ficam esses mesmos territórios, a dificuldade de entrada nos territórios, e por último, a perigosidade desses lugares.

\begin{tabular}{|c|c|c|c|c|c|c|}
\hline $\begin{array}{l}\text { ENTREVISTADOS } \\
\text { (PSEUDÓNIMOS) }\end{array}$ & $\begin{array}{c}\mathrm{N}^{\circ} \\
\text { TERRITÓRIOS }\end{array}$ & $\mathrm{N}^{\circ}$ VISITAS & $\begin{array}{c}\mathrm{N}^{\circ} \text { TOTAL } \\
\text { NoITES/DIAS }\end{array}$ & $\begin{array}{c}\text { DISTÂNCIA } \\
\text { PERCORRIDA }\end{array}$ & Vistos & Perigosidade \\
\hline Manuel & 5 & 5 & 4 & 1 & 3 & 1 \\
\hline Rita & 3 & 3 & 3 & 2 & 2 & 2 \\
\hline Maria & 5 & 4 & 4 & 4 & 2 & 1 \\
\hline Mariana & 3 & 3 & 2 & 1 & 3 & 4 \\
\hline Teresa & 4 & 1 & 4 & 4 & 1 & 4 \\
\hline João & 4 & 2 & 3 & 5 & 1 & - \\
\hline António & 5 & 5 & 5 & 5 & 5 & 5 \\
\hline José & 2 & 4 & 2 & 1 & 3 & 2 \\
\hline Total & 31 & 27 & 27 & 23 & 20 & 19 \\
\hline
\end{tabular}

Tabela 2: O peso dos critérios na perspetiva dos viajantes entrevistados

Quase todos estes viajantes contabilizam as suas viagens, mesmo que isso não seja central ou o que despoleta a viagem. João, arquiteto que trabalha numa Câmara Municipal, é talvez o viajante mais organizado e afirma que contabiliza todas as suas viagens. Diz que "antes de viajar, e tendo em conta o tipo de viagens que faço, produzo sempre um dossier de preparação e estudo do território que irei atravessar. Aí, de certa forma, ficam guardados os lugares que irei percorrer. Depois, e como levo sempre cadernos de viagem, vou desenhando à medida que viajo. Agora não marco num mapa, como muita gente, os lugares onde já estive. As viagens e os lugares ficam todos no meu interior...não sinto necessidade de os expor dessa forma...num mapa". O mapa como 
forma de representação dos lugares por onde os viajantes já estiveram é comum a três dos oito viajantes. Rita, que trabalha para as Nações Unidas em África, afirma "tenho um mapa em que o formato do país que visitei tem uma foto minha tirada lá. O mapa foi feito por mim". Maria, funcionária do Ministério dos Negócios Estrangeiros destacada na União Europeia, inicialmente não contava os países que visitava, e apenas os listava no telemóvel. Mas decidiu começar a assinalar num mapa todos os países que visitou quando estes começaram a ser numerosos. Finalmente António, um viajante independente "mochileiro", conta os países de uma forma muito simples, através de um mapa, colorindo os países visitados.

Teresa, docente universitária, tal como José, um viajante profissional que trabalha para uma agência de viagens alternativas, e Manuel, um viajante que faz missões religiosas e militares, sobretudo em África, referem que contabilizam os países apenas mentalmente. José refere que não tem por hábito contar as suas viagens, uma vez que sabe de cor quais são, e diz não atribuir grande importância ao número de territórios visitados, pois valoriza outro tipo de contabilidades. Nas suas palavras: "Marco, mais do que lugares, experiências que passei e pessoas que conheci: o Pachu na Noruega, o Pal na Índia, o Sahar no Irão, e a Jasmine na Arménia!". Esta é uma perspetiva muito diferente da adotada neste texto, mas igualmente interessante e que indica a variedade de formas como as pessoas registam e são marcadas pelas viagens. Manuel vai fazendo várias coleções de objetos de diversos países, tais como chávenas, pratos, selos, moedas, etc. A sua contabilidade, ainda que possa não ser muito precisa, faz-se através destas coleções, que constituem também uma narrativa das suas viagens. De forma semelhante, Mariana, empresária da moda e vestuário, também não contabiliza as suas viagens, mas coleciona ímanes alusivos às cidades/países visitados que indicam e registam estas viagens. Em casa, na porta do frigorífico estes ímanes, souvenirs banais, são decorativos, mas constituem também uma marca e símbolo de um estatuto contemporâneo de mobilidade (Peters, 2011). Rita coleciona tudo o que pode, "desde jornais, informação sobre o país (turística e política), livros sobre o país, mapas, postais - no último dia envia sempre por correio um postal para si, com aquilo que sente por aquele país". Já Maria refere que quando viaja gosta sempre de trazer uma recordação nem que seja simbólica e sem qualquer valor, dependendo do sítio em questão. Uma vez que gosta muito de arte, procura trazer sempre objetos relacionados com o tema, nomeadamente pinturas. João, para além de produzir o seu próprio dossier e dos desenhos que elabora, coleciona outro tipo de objetos tais como os bilhetes de metro ou avião, para depois servirem de marcadores de livros que leva para a viagem ou que compra durante a viagem. Também guarda água do grande canal de Veneza e areia de Wadi Rum (Jordânia), mas confessa que os seus objetos preferidos são os desenhos que faz durante as viagens.

José e António, em parte por viajarem muitas vezes de bicicleta ou de mochila às costas, têm uma relação diferente com objetos, e o volume e peso que eles acarretam. O primeiro diz que sempre que pode traz chapéus de vários países, pedaços de cartazes que arranca da rua, postais ou papéis de pessoas que the escrevem. O segundo refere que coleciona algo bem mais importante para ele: "histórias e as vivências em cada país. 
Muitas delas, histórias bem engraçadas por ser um habitat completamente diferente do nosso". Por fim, Teresa diz que cada vez compra menos coisas nas suas viagens, alegando que a tendência é o afastamento dos bens materiais.

Naturalmente que as caraterísticas diferenciadas dos viajantes explicam estas diferenças internas nos resultados. José desvaloriza a distância percorrida para chegar a um destino, pois na verdade esta depende muito dos modos de transporte utilizados. Ele, que muitas vezes viaja de bicicleta, diz simplesmente que chegar à Nova Zelândia de avião é muito mais simples e rápido que ir aos Pirenéus de bicicleta. Já Mariana, pela quantidade de viagens que faz, passou a ser um pouco imune a esta dimensão, não a valorizando, e afirmando que faz parte integrante do que é a viagem, dando mais importância à perigosidade do destino. Ao invés, Manuel, Rita e Maria, que viajam no âmbito de missões organizadas, não valorizam a perigosidade dos destinos como outros viajantes, pois as suas viagens têm redes de segurança específicas. Os vistos, explicam, também não são um constrangimento, pois nem sequer tratam desta dimensão da viagem. O que estas experiências nos indicam é que a diversidade de viajantes que escoIhemos valoriza de forma muito diferenciada aspetos vários das viagens. $O$ índice que aqui propomos, não é o mais adequado para quem maioritariamente viaja de bicicleta, quem viaja integrado em missões profissionais, ou outros tipos particulares de viagens. É um índice genérico, que pretende acima de tudo estimular a discussão em torno do que é viajar.

\section{Conclusão}

O trabalho aqui apresentado pretendeu discutir as viagens enquanto coleções. No contexto das coleções enquanto práticas sociais, e partindo das formas de contabilização de viagens que diversos organismos e plataformas construíram, propôs um índice que engloba variáveis que nos parecem importantes, mas que são normalmente descartadas: o número de vezes que se visita um território e o tempo de permanência, e algumas caraterísticas desse mesmo território. Outras variáveis foram equacionadas, mas não incluídas no índice por levantarem complexidades de operacionalização: a distância linguística e cultural entre a origem e o destino foi referida nas nossas discussões, bem como a aprendizagem de uma ou mais línguas por causa das viagens. Ambas podem enriquecer o índice.

Idealmente poder-se-ia conceber uma aplicação móvel que permitisse aos viajantes introduzir os seus dados de modo simples e autónomo. A ligação dinâmica a bases de dados permitiria calcular instantaneamente as distâncias tempo em diversos momentos, e sobretudo considerar a origem noutras cidades que não o Porto, como aqui se fez. Ao mesmo tempo, poder-se-iam fazer cálculos com passaportes distintos, estabelecendo ligação a bases de dados com este tipo de informação. A variável perigosidade e dificuldade de entrada num território, que estão associadas ao tempo presente e não à data em que se visitou esse território, poderiam também ser calculadas com mais precisão, adquirindo um interesse acrescido no cálculo do índice aqui proposto. 
Muitos viajantes contabilizam os lugares que visitam de diferentes formas: colecionando objetos, contando histórias das suas viagens, com mapas de pins, partilhando fotografias nos seus blogues e redes sociais, entre outros. Também há viajantes que optam por fazer esta contabilidade em plataformas, possibilitando assim uma contagem bastante simples dos lugares que visitam. O trabalho aqui apresentado faz uma reflexão sobre estas contabilizações propondo uma forma mais completa ou complexa de contabilização, que serve, acima de tudo, para discutir o tema das viagens, e não para cristalizar uma fórmula ou índice cego. Para além destes contributos, o trabalho promoveu a discussão da divisão territorial do mundo, com as suas implicações geográficas, políticas e sociais, que em muito ultrapassam a questão do turismo e das viagens.

\section{REFERÊNCIAS}

Anderson, B. (2006). Imagined communities: reflections on the origin and spread of nationalism. Londres: Verso.

Beeton, S. (2016). Film-induced tourism. Clevedon: Channel View publications.

Belk, R. (2006). Collectors and collecting. In C. Tilley, W. Keane, S. Küchler, M. Rowlands \& P. Spyer (Eds.), Handbook of material culture (pp. 534-546). Londres: Sage.

Cresswell, T. (2014). Place: an introduction. Londres: John Wiley \& Sons.

Elden, S. (2010). Land, terrain, territory. Progress in Human Geography, 34(6), 799-817.

Gosch, S., \& Stearns, P. (2008). Premodern travel in world history. Londres: Routledge.

Heffernan, M. (2003). Histories of geography. In S. Holloway, S. P. Rice \& G. Valentine (Eds.), Key concepts in Geography (pp. 4-22). Londres: Sage.

Jansson, A. (2017). Mediatization and mobile lives: a critical approach. Londres: Routledge.

King, L. M.\& Prideaux B. (2010). Special interest tourists collecting places and destinations: a case study of Australian Word Heritage sites. Journal of Vacation Marketing, 16(3), 235-247.

Lessing, D. (1994). Under my skin. Nova lorque: HarpperCollins.

Livingstone, D. N. (1991). Of design and dining clubs: Geography in America and Britain, 1770-1860. Science History Publications Ltd, (73) 91, 153-183.

Livingstone, D. (1992). The geographical tradition: episodes in the history of a contested enterprise. Oxford: Wiley-Blackwell.

Pearce, S. (1992). Museums, objects, and collections: a cultural study. Leicester: Leicester University Press.

Peters, K. (2011). Negotiating the 'place'and 'placement' of banal tourist souvenirs in the home. Tourism Geographies, 13(2), 234-256.

Sánchez, J. (2018). Jorge Sánchez-Viajero. Retirado de http://jorgesanchez.es/the-best-travelers-of-the-world/.

Sheller, M., \& Urry, J. (2006). The new mobilities paradigm. Environment and planning A, 38(2), 207-226.

Timothy, D. (1998). Collecting places: geodetic lines in tourist space. Journal of Travel a Tourism Marketing, 7(4), 123-129. 
Urry, J. \& Crawshaw, C. (2002). Tourism and the photographic eye. In C. Rojek (Ed.), Touring cultures (pp. 186205). Londres: Routledge.

Wulf, A. (2016). A invenção da natureza. As aventuras de Alexander von Humboldt. Lisboa: Temas \& Debates.

\section{NOTAS BIOGRÁFICAS}

João Sarmento, Geógrafo, doutorado em Geografia pela Universidade de Cork, Irlanda (2001), tem investigado e publicado nas áreas da Geografia Cultural, Geografia do Turismo, Geografia Urbana e Geografias Pós-Coloniais. Departamento de Geografia e CECS, Universidade do Minho

Email: j.sarmento@geografia.uminho.pt

Morada: Departamento de Geografia, Universidade do Minho, Campus de Azurém, 4800-055 Guimarães, Portugal

Patrícia Lopes, Geógrafa, Mestre em Geografia, especialização em Planeamento e Gestão do Território pela Universidade do Minho (2018), fez a sua tese de mestrado sobre viagens e viajantes. Actualmente trabalha para a empresa EixoCardinal.

Email: patriciadplopes@outlook.com

Morada: R. Dr. Cal Brandão, 4445-101 Alfena, Portugal

* Submetido: 28-02-2018

$*$ Aceite: 09-05-2018 